\title{
Multimedia materials for education, training, and advocacy in international health: experiences with the Schistosomiasis Control Initiative CD-ROM
}

\author{
TJ Beanland $/{ }^{+}$, SD Lacey, DD Melkman, S Palmer, JR Stothard*/**, F Fleming**, \\ A Fenwick**
}

Publishing Group - International Health, Wellcome Trust, 215 Euston Road, London NW1 2BE, UK *Department of Zoology, Natural History Museum, London, UK **Schistosomiasis Control Initiative, Department of Infectious Disease Epidemiology, Imperial College London, UK

We describe an innovative use of multimedia materials to support training and advocacy within a schistosomiasis control programme. The Schistosomiasis Control Initiative (SCI) at Imperial College London works with selected sub-Saharan African countries to develop schistosomiasis control programmes. Two elements of the SCI programme were supported by multimedia materials developed at the Wellcome Trust in collaboration with the SCI: (1) training of programme managers, district health officers, and those delivering practical elements of the programme; and (2) advocacy targeted at decision-makers and donors. Evaluation of the materials revealed high reported ratings for both user satisfaction and impact from use of the product. From this experience we draw out several general messages about development of multimedia materials and how these will play a growing future role in promoting training within international health.

Key words: educational technology - multimedia - public health - schistosomiasis - communicable disease control

The lack of accurate, accessible, and high quality training materials for healthcare professionals in many lowincome settings is widely recognised (Godlee et al. 2004). The G8 Digital Opportunity Task Force (2002) identified education and training of healthcare professionals as one of three areas where information and communication technologies (ICTs) can bring health benefit to developing countries. This opportunity was supported by calls for renewed investment in ICTs at the Tunis World Summit on the Information Society in November 2005. It is also widely recognised that knowledge management through ICTs has an important role to play in bridging the ' $k$ nowdo' gap which exists between knowledge and practice (Sachs 2005).

Recent work (Hotez et al. 2006) has highlighted the relative neglect by the international community of some tropical diseases (e.g. trypanosomiasis, leishmaniasis, Chagas disease) over others, notably the Global Fund trio of malaria, tuberculosis, and HIV/AIDS. These neglected diseases include schistosomiasis, for which the global burden is estimated at more than 200 million people infected, 20 million living with severe chronic health consequences, and 20,000 deaths annualy. Some $85 \%$ of the 200 million people infected with schistosomiasis live in sub-Saharan Africa, where both intestinal and urinary forms of the disease occur (Van der Werf et al. 2003).

Financial support: The Wellcome Trust, Schistosomiasis Control Initiative via the Bill and Melinda Gates Foundation

${ }^{+}$Corresponding author: pgih@wellcome.ac.uk.

Received 25 May 2006

Accepted 26 June 2006
At the Fifty-fourth World Health Assembly in 2001, nearly 200 countries endorsed a resolution on schistosomiasis and soil-transmitted helminths (STHs), which included the goal, to be met by 2010 :

"to regularly treat at least $75 \%$ of all school age children at risk of schistosomiasis and soil-transmitted helminth infections".

We describe our experiences at the interface between these two areas, using ICTs to support delivery of training and advocacy messages within a schistosomiasis control programme. Although the work we report is primarily in support of schistosomiasis control focused on Africa, the approach and many of the principles can be generalised to other diseases and wider settings.

\section{METHODS}

Multimedia development at the Wellcome Trust - The Wellcome Trust (www.wellcome.ac.uk) is a privately endowed charity which is independent of political or commercial interest. Its mission is to foster and promote research with the aim of improving human and animal health. The Wellcome Trust funds research, including research into many tropical diseases, and works to encourage the application of research knowledge for health benefit. The development of educational and training materials in international health at Wellcome has helped to support this aim for more than 10 years.

The Wellcome Trust multimedia development team has two broad strands of activity (Table). To date these materials have been almost exclusively on CD-ROM, largely because of the low levels of affordable internet, especially broadband, connectivity in many developing countries, notably those in Africa. The materials are fully interactive multimedia, with text, animations, videos, audio, and hundreds of high-quality images. 
TABLE

Wellcome Trust multimedia materials in international health ${ }^{a}$

\begin{tabular}{|c|c|c|}
\hline & 'Topics in International Health' CD-ROMs & Collaborative CD-ROMs \\
\hline 'Ownership' & Wellcome Trust & $\begin{array}{l}\text { Partnership between Trust and external not-for-profit } \\
\text { organisation }\end{array}$ \\
\hline Examples of titles & $\begin{array}{l}\text { Dengue, malaria, leishmaniasis, diarrhoeal } \\
\text { diseases, HIV/AIDS, tuberculosis }\end{array}$ & $\begin{array}{l}\text { Schistosomiasis Control Initiative, Elimination of Lymphatic } \\
\text { Filariasis, Trypanosomatids: Genomes and Biology }\end{array}$ \\
\hline Target audience & $\begin{array}{l}\text { Trainee doctors, biomedical science students; } \\
\text { researchers and teachers of these groups }\end{array}$ & $\begin{array}{l}\text { Programme managers, } \mathrm{MoH} \text { officers and other decision- } \\
\text { makers working within a disease control programme }\end{array}$ \\
\hline Aim & $\begin{array}{l}\text { Educational: give an accessible and up-to-date } \\
\text { summary of each disease }\end{array}$ & Training: promote skills. May also include advocacy \\
\hline Content & $\begin{array}{l}\text { Didactic tutorials; searchable image collection; } \\
\text { glossary; self-assessments }\end{array}$ & Training tutorials; 'toolbox'; resources. Advocacy messages \\
\hline Distribution & $\begin{array}{l}\text { By Wellcome Trust. Free to individuals in } \\
\text { low-income countries, charged to developed } \\
\text { world }\end{array}$ & $\begin{array}{l}\text { Largely by partnering organisation, often through the } \\
\text { control programme }\end{array}$ \\
\hline
\end{tabular}

$a$ : for more details, see www.wellcome.ac.uk/knowledgecentre/cdroms

The Schistosomiasis Control Initiative - The Schistosomiasis Control Initiative (SCI, www.schisto.org) is an independent unit at Imperial College London, set up in 2002 with a 5 year grant from the Bill and Melinda Gates Foundation. The SCI works with Ministries of Health in selected sub-Saharan African countries to develop and implement sustainable schistosomiasis control programmes. The key element of these programmes is mass drug treatment of school children and other high-risk groups to control morbidity, and to reduce the prevalence and intensity of infections with schistosomes and STHs (Fenwick 2006).

The SCI decided that some elements of its activities, including development of control programmes in Africa, could be supported in an innovative manner using ICTs. They approached the multimedia team at the Wellcome Trust to form a partnership, to develop training and advocacy materials in support of the programme. A key result of this partnership is the Schistosomiasis Control Initiative CD-ROM.

\section{The SCI CD-ROM}

Aims and target audiences - Two elements of the SCI programme were supported through use of multimedia. The first is the training of programme managers, district health officers and those responsible for delivering practical elements of the schistosomiasis control programme. The SCI CD-ROM aimed to meet the need for accurate, timely and consistent information among these individuals 'on the ground', whose job it is to see that the schistosomiasis control programmes are successful. Through a combination of interactive didactic multimedia materials and resources, the $\mathrm{CD}$ was used in training to help develop a consistent skill set among these personnel.

The second programme element supported by the CDROM was advocacy targeted at decision-makers and donors. The aim here was to raise awareness about schistosomiasis and the scale of the problem, among the people who make decisions and who have the power to make changes. In this section the materials were carefully streamlined to provide the maximum information impact within the shortest time for structured use.

The full title of the SCI CD-ROM reflects these dual aims: 'Schistosomiasis Control Initiative: Advocacy and Training Interactive Guide' (Figure).

Structure and content - The audiences were targeted with a tailored blend of multimedia materials which combined text, photographs, video, animation, and audio formats. These materials were structured under five headings: key advocacy messages (to influence the opinions and actions of important individuals to gain political and societal commitment); detailed training information on developing and implementing a national programme; a treatment training kit to 'train the trainer'; a toolbox of skills-based, 'hands-on' programme-related information; and easily accessible resources to complement and extend the advocacy and training components.

Because of the two key target audiences, the CD was structured with a high-level division into training and advocacy sections. Content, 'tone of voice' and functionality within each of these were all tailored to the specific needs of the different target audiences.

Development - In development of the product, the partnership played to the strengths of the two collaborating organisations. The Wellcome team brought experience in multimedia development, from initial needs assessment through conceptual design to scoping, content creation and technical development. The SCI team brought scientific expertise in schistosomiasis, detailed knowledge of the programme and links to users on the ground. SCI staff in Tanzania, Uganda, and Zambia also provided assistance in various evaluations.

At two key stages in the production of the CD-ROM, feedback was sought from users to inform development of the product. An initial 'taster' product was developed for a meeting in London of SCI programme managers. A more developed 'pilot' CD was then trialled at a meeting 


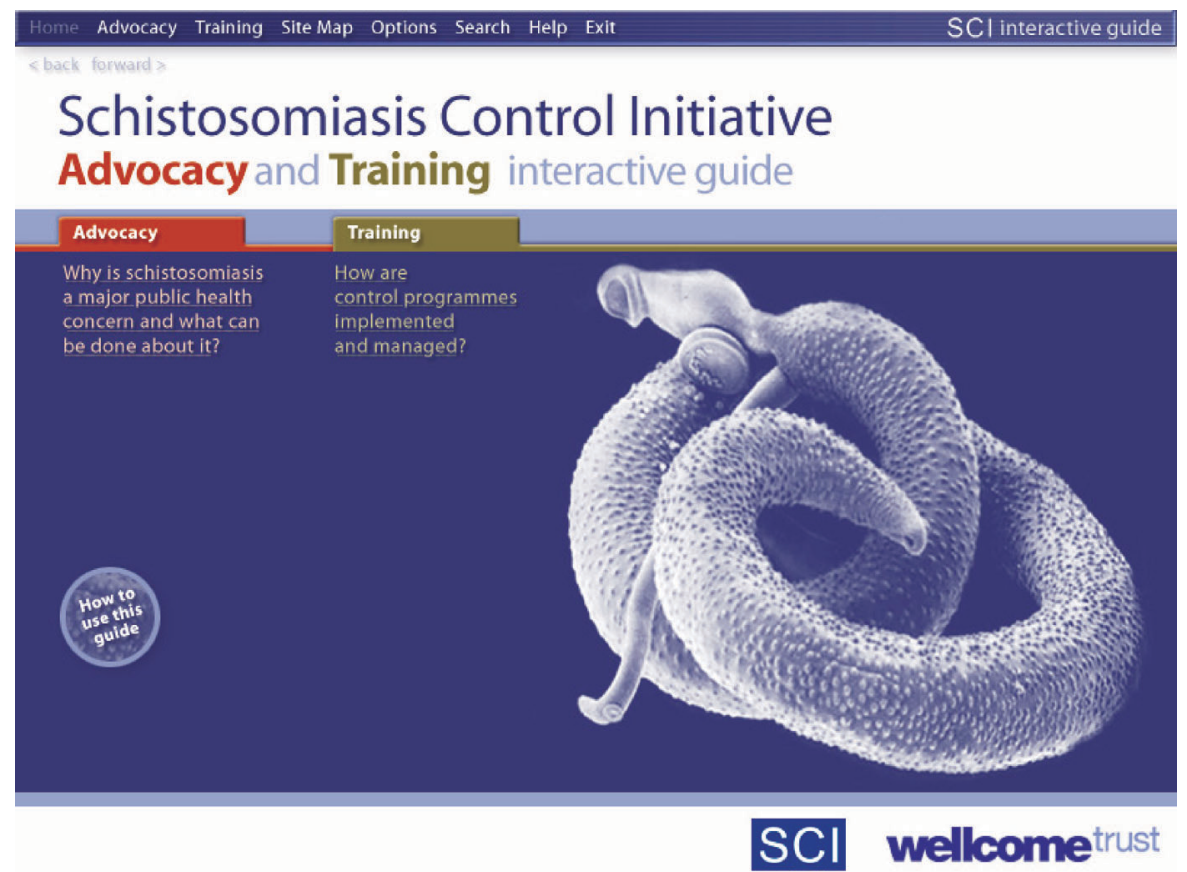

The 'home' screen of the Schistosomiasis Control Initiative CD-ROM, showing the key division into advocacy and training materials.

in Tanzania of the in-country team, who acted as a focus group of representative users. This pilot evaluation showed, for example, that some of the proposed multimedia functionality needed to be made much clearer to suit the IT skills of the intended target audience. Navigation through the $\mathrm{CD}$ content emerged as a particular issue, which was addressed by development of a sophisticated but user-friendly site-map.

Distribution and use - A wide range of individuals have used the finished CD-ROM. Within the SCI-supported countries, the $\mathrm{CD}$ was integrated into training of programme staff such as programme managers and control programme technical staff, health workers, schoolteachers, and community drug distributors as part of national control activities (see 'Evaluation'). Further CDs were distributed to doctors and other health professionals with Medical Education Resource Africa, a journal for African doctors.

The CD was also distributed freely worldwide to a wide range of policy-makers, research funding bodies, international development agencies and non-governmental organisations. The aim here was to raise awareness of schistosomiasis and the SCI programme. The $\mathrm{CD}$ was pro-

\footnotetext{
${ }^{1}$ Copies of the CD may be requested from the SCI by email (schisto@imperial.ac.uk) or from Schistosomiasis Control Initiative, Department of Infectious Disease Epidemiology, Imperial College London, St Mary's Campus, Norfolk Place, London W2 1PG, UK . A French-language version of the CD, developed for francophone Africa, may be obtained from the same address.
}

moted using a mixture of techniques (websites, email lists, attendance at meetings, and so on).

A very positive review of the $\mathrm{CD}$ in the Lancet (Savioli 2005) led to a large number of requests for copies, such that to date over $2000 \mathrm{CDs}$ are in use ${ }^{1}$. A survey suggested an average of 7 people using each SCI CD, taking the number of users above 15,000 .

\section{RESULTS}

Summative evaluation - The SCI CD-ROM was a key part of a formal wide-ranging evaluation of Wellcome Trust multimedia international health products carried out in 2005. The aim of this exercise was partly to gather feedback from users to support future product development, and partly to assess impacts of the CDs on training.

The majority of those who had received the SCI CDROM had internet access, and so the survey was done online. Some 143 people who had received the CD (often multiple copies) were emailed and 54 completed replies received, a response rate of $38 \%$. The survey asked for details of how and where the $\mathrm{CD}$ was being used, what users thought of the materials and - perhaps most important - perceived impacts from use of the CD. These impacts included whether the users thought that the $C D$ had increased awareness of schistosomiasis or STHs, whether it had improved training elements of the control programme, and whether it had helped produce improvements in health.

User ratings for a range of quality issues were rated on a four-point scale. Levels of satisfaction with the CD (combining those who were 'very satisfied' or 'fairly satisfied') were almost universally high: $96 \%$ for design and layout of information; $92 \%$ with the quality and reliability of the content; $86 \%$ for the content being up to date, for 
example $(\mathrm{n}=52)$. What was more surprising about the feedback were the high impact levels reported. For example, $65 \%$ of respondents reported that the $\mathrm{CD}$ had improved training and nearly half of users (49\%) that it had led to improvements in health. (The latter figure is within 3 percentage points of the equivalent figure for evaluation of the Trust's 'Topics in International Health' CDROMs. It may be that, by supporting training so close to disease control activities, the products can have a direct impact on delivery by healthcare professionals.).

To complement the quantitative survey with a more narrative approach, a series of case studies were carried out. One such on use of the SCI CD in Zambia, conducted with the in-country SCI coordinator, largely reinforced the findings from the online survey, but also provided greater insight into how the product was perceived and used 'on the ground'. A sample quote from this case study is:

"animations and videos are particularly clear and helpful. They give a strong impression of a subject but also allow for extra, country-specific, information to be given".

Other elements of the evaluation, such as consultations and detailed analysis of distribution data, are not specifically reported here but can be obtained from the authors on request.

\section{DISCUSSION}

In making some general conclusions, we draw on experience not just from the SCI CD-ROM project but from more than 10 years of developing multimedia education and training materials in international health at the Wellcome Trust. So doing, we hope to draw out several general messages of relevance to a wider audience.

A key consideration is that the technological elements of multimedia development should flow from, rather than drive, considerations of target audiences or learning/training outcomes. Our experience also reinforces the need to work closely with users in product development to ensure that the materials accurately reflect their needs and expectations. It is vital to be clear at the outset of the project about the target audience and the high-level objectives that the product seeks to achieve, and to revisit these regularly to avoid 'mission creep'. In our experience the two main areas why products fail to deliver are in technical implementation (it was 'fun' or just possible) and around content (it was deemed to be 'interesting' but was actually not relevant for the stated audience).

One feature of multimedia development which is reinforced by this experience is the iterative nature of production, by which functionality is developed, tested, then refined. Of all aspects of multimedia development, navigation through the materials is among the most important. The balance to strike is between offering navigational flexibility, so that the user can create their own route through the materials, and enforced navigation - to prevent users, especially first-time users, getting lost. Clear guidance and 'signposting', through both textual and design cues, are essential.
It is instructive for those thinking of entering this field to reflect on the effort required to develop multimedia materials of this depth and richness. In our experience the only sustainable approach is to have a dedicated team working across the entire production cycle from concept to delivery, and doing so on a full-time basis. This said, partnerships between this production team and external organisations are an invaluable way to build for greater impact. Such partnerships are a key feature of the SCI CDROM, not just between the Wellcome Trust and the SCI, but extending more widely, for example to Partners for Parasite Control at WHO (www.who.int/wormcontrol/en).

There are some weaknesses of the approach taken. Not least of these is the demands placed on end users for computer facilities. Although the SCI programme, as with some other Gates-funded projects, is technologically well supported, CD users at some training sites could not access the materials due to lack of reliable electricity supplies. It is less of a weakness that the product requires modest levels of IT literacy to use, as in our experience such training materials can help drive development in this area because users are more motivated to learn. Having the materials in English is a potential barrier in some settings, overcome in this case by producing a French-language version for francophone Africa. Some of the other Wellcome CDs have been translated and there are plans to translate more, including Portuguese versions of some titles developed in collaboration with FIOCRUZ in Rio de Janeiro (Pimenta et al. 2005).

\section{ACKNOWLEDGMENTS}

To those who took part in the evaluation work described, and for permission to use quotes. The evaluation work was carried out by the Strategic Planning and Policy Unit at the Wellcome Trust.

\section{REFERENCES}

Digital Opportunity Task Force 2002. ICT for Health.

Fenwick A 2006. New initiatives against Africa's worms. Trans $R$ Soc Trop Med Hyg 100: 200-207.

Godlee F, Pakenham-Walsh N, Ncayiyana D, Cohen B, Packer A 2004. Can we achieve health information for all by 2015? Lancet 364: 295-300.

Hotez PJ, Molyneux DH, Fenwick E, Ottesen E, Sachs SE, Sachs JD 2006. Incorporating a rapid-impact package for neglected tropical diseases with programs for HIV/AIDS, tuberculosis and malaria. PloS Med 3: e102.

Pimenta DN, Beanland TJ, Schall VT, Pinto Dias JC 2005. Moving from information transfer to information exchange: evaluation and production of electronic training materials on dengue and Chagas' disease. ICML-9/CRICS7, Salvador-Bahia, 20-23 September.

Sachs JD 2005. The End of Poverty, Lecture, London, 10 November.

Savioli L 2005. Schistosomiasis maze. Lancet 365: 1680.

Van der Werf MJ, de Vlas SJ, Brooker S 2003. Quantification of clinical morbidity associated with schistosome infection in sub-Saharan Africa. Acta Trop 86: 125-139. 